\title{
Karate-do Athletes' Reactions to Aggression and Motivation during Fit and Well Zone Tournament Performance
}

\author{
Lowelyn L. Mabandes, $\mathrm{MSPE}^{1}$, Stephen A. Fadare, EdD ${ }^{2}$, Hendely A. Adlawan. $\mathrm{PhD}^{3}$ \\ ${ }^{I}$ Department Chairman, CSPEAR, Mindanao State University (Main), Philippines \\ ${ }^{2}$ Research Committee, CSPEAR, Mindanao State University (Main), Philippines \\ ${ }^{3}$ Dean CSPEAR, Mindanao State University (Main), Marawi, Philippines.
}

\begin{abstract}
This descriptive-type study assessed the profile of the respondents along; age, gender, length of training, highest level of participation in fighting karate-do games. More so, looking into the level of aggression and level of motivation as factors that influence the participants in karate-do tournaments in the city of Cagayan de Oro. The data were gathered using questionnaire and observation, and were treated using frequency count, and t-ratio for $r$. Correlation among the variables was determined, as well as the capabilities of aggression and motivation of the respondents. It was found out that the respondents were withing the age of $18-21$ years old, and majority were male. It also revealed their length of training to be 1-5 years while their highest level of participation in the game was in the National tournament. The participants level of aggression and motivation was very high aggressive and highly motivated. It was concluded that while the participants in karate-do tournaments fight in national tournaments, their capability still needs to be enhanced and support by various organizations that are involved.
\end{abstract}

Keywords: Aggression, Motivation, Fit and Well Tournament, Karate Athletes, sport performance, varsity athletes.

\section{INTRODUCTION}

Sports appear to be taking up an increasing amount of time in everyone's lives. Every individual has an innate need to participate and engage in some form of physical activity and sports programs to develop their potential and skills in sports. Thus, sport is defined as institutionalized competitive activities that involve vigorous physical exertion (Coakley, 2009).

The practice of sport provides choices to be made based on social class. Many famous team sports only require bodily and cultural competencies that are relatively equally distributed, not only the social composition of their public, which redoubles their commonness, but also the values and virtues demanded: strength, endurance, violence, sacrifice, docility, submission to collective discipline, and the exaltation of competition (Kordi et al., 2009).

Karate, in Japanese, means 'empty hand' is an unarmed sport method wherein an individual throws a punch, scares, tries to kick, or strips. Karate originated in the 1600s on the Japanese island of Okinawa, as te (meaning'hand'), and earlier methods of Chinese kung fu directly influenced it. Funakoshi Gichin, an Okinawan school teacher, known as the father of modern Karate, brought martial art to Japan in 1922. Funakoshi added a solid philosophical element to Karate, creating a separate martial art called karate-do that pays more attention to the student's state of mind. For example, no matter their skill level, practitioners must not brag or demean other students (World Karate Federation, 2012).

In the Philippines, martial arts are taught and practiced by both men and women. combat among neighboring tribes and warlords. The Filipinos, on the other hand, take pride in believing that their martial arts are a selforiginated art, not one borrowed from the Chinese, Koreans, Japanese, or Spaniards.

The Republic Act RA No. 9850, an Act declaring Arnis as the Philippines' national Martial Art and sport, was signed into law in 2009. The Philippine Karate-do Federation was a member of the World Karate 
DOI: $\underline{10.51386 / 25815946 / \mathrm{ijsms}-\mathrm{v} 4 \mathrm{i} 3 \mathrm{p} 119}$

Volume: 4 Issue: 3

May to June 2021

www.ijjsmsjournal.org

Federation Children and adults, primarily in the Lanao Del Sur, BARMM region, were not left behind in participating or enrolling to be trained in the sport of Karate-do. They find it fun and are ready to wear their uniform, which is white over the different colors of the belt, as they go on to intensify their practice and fight against other opponents.

Researchers' findings will help sports psychologists, schools, universities, college coaches, trainers, and sports managers understand how aggression and motivation can help athletes achieve their hearts' desire during their tournaments. Specifically, it looked into the profile of the respondents in term of their age, gender, length of training, highest level of Participation, level of aggression and level of motivation.

\section{LITERATURE REVIEW}

\section{A. Aggression}

The word "aggression" literally means "aggressio," which implies "attack" (Cashmore, 2002). Aggression is defined as "a forceful, goal-directed action, either verbal or physical, that is the motor counterpart of the effect of rage, anger, or hostility" (Sadock, 2009). Although many participants in sports have many positive aspects, championship tournaments are usually accompanied by aggressive behavior (Cashmore, 2002). The two types of aggression are: hostile and instrumental. The goal of negative or reactive aggression, which is motivated by anger, is to cause physical or psychological harm to others. The purpose of instrumental aggression is beyond the infliction of injury on the other player, and the awareness or intention of damage is incidental (Wann, 2005).

Karate, as an aggressive sport for self-defense, has, in recent decades, increased worldwide. It is now the most widely practiced Oriental martial art, with a large following in Japan, the U.S., and Europe, which teaches its students to have the self-confidence, self-discipline, and self-control skills necessary to function in today's world. Therefore, it has been referred to as oriental martial arts rather than Japanese martial arts, not only because of the apparent origins of the arts, but also because the cultural interaction between Japan and China has been so strong that it is difficult to distinguish one from the other (Sudesh \& Rathee, 2013).

Aggression among athletes can be curtailed or at least minimized if all concerned are interested in doing so. The painful part is that some of the most influential people promote rather than discourage violence because they believe it sells tickets. As this attitude is allowed to continue, there is little hope of solving the problem. Cox (2002) stated that boxing is an example of a sport whose goal is to inflict physical harm on the opponent. If it is allowed to continue at the professional level, it will continue to be promoted at the lower skill levels. Athletes in the youth leagues emulate their heroes at the collegiate and professional levels. They see their sports heroes receive awards, applause, money, and adoration for aggressive behavior and aspire to be like them.

In competitions, it can be hard to differentiate between aggression and assertion. Although assertive behaviors are forceful behaviors that are not intended to injure the victim, they may cause unintended harm to the athlete's opponent due to their nature. Furthermore, some sports involve forceful physical contact that has the potential to harm another person, but this contact is permitted by the rules of the game. Assertive behaviors have also been referred to as sanctioned aggression. Thus, sanctioned aggression is defined as any behavior that falls within the rules of a specific sport or is widely accepted as such, such as using the shoulder to force a player off the ball in soccer or tackling below the shoulders in rugby. Combat sports such as judo, karate, and wrestling are examples, as are team contact sports such as rugby, ice hockey, American football, and lacrosse. Perhaps the confusion between assertion and aggression arises because both have the potential to harm the target, though, as previously stated, only aggression involves the intent to harm.

Researchers found out about aggression in athletes who exercise in high physical contact sports, like football players, judokas, or wrestlers. They were more aggressive in both sports and in their daily lives (BasiagaPasternak et al, 2020). Parallel studies of various sports were conducted in support of the theory. The findings revealed that practicing military skills reduces levels (BlomqvistMickelsson, 2020). Martial arts have been proposed by some researchers as a method of developing emotional and behavioral self-control (BlomqvistMickelsson, 2020). Others, on the other hand, have claimed that karate training will not result in a decrease in aggression (Hernandez, 2015). 
DOI: $\underline{10.51386 / 25815946 / \mathrm{ijsms}-\mathrm{v} 4 \mathrm{i} 3 \mathrm{p} 119}$

Volume: 4 Issue: 3

May to June 2021

www.ijjsmsjournal.org

\section{B. The Scope of Aggression}

The concept of intent, which is included in most definitions of aggression, has made measuring aggression difficult that many studies have operationally defined and measured aggression without taking intent or motivation into account.

Aggression has been measured in sports in various ways, including the number of fouls, coach ratings, penalty records, self-reports, and behavioral observation. In addition, instrumental and hostile aggression have been measured in behavioral observation studies. Structurally, constructive aggression is defined as aggression that occurs during gameplay and consists of opponent-directed physical interactions that aid in the completion of a task.

On the other hand, hostile aggression has been operationally defined as physical or verbal interactions aimed at multiple attacks but not directly related to task completion; these behavior patterns are aimed at opponents, teammates, or referees. Repelling, hitting, and cheating, for example, have been coded as instrumental aggression in handball, while insulting, threatening, obscene gestures, and shoving against opponents, referees, teammates, and others have been coded as hostile aggression. Aggressive behaviors (e.g., late tackling, hitting, elbowing) have also been measured as part of the antisocial behavior construct, which has been defined as behavior intended to harm or disadvantage another individual and has significant overlap with aggression.

Many researchers have been using athletes' self-reports to measure aggression, either by presenting them with a physical aggression scenario and asking about their intentions or the likelihood of an aggressor or by asking them to acknowledge a series of items measuring aggressive or antisocial behavior.

As a proxy for aggression, a self-described likelihood of aggressing has been used. For example, several studies are presented with a scenario in which the protagonist is faced with harming the opponent to prevent scoring. In addition, to indicate the likelihood that they would engage in this behavior if they were in this aggression situation (e.g., attempting to injure another player) has been assessed as a component of antisocial behavior in sports.

\section{Motivation}

Motivation and aggressive behavior, on the other hand, come in a variety of shapes and sizes. The word motive is the root of the word motivation. This word's Latin equivalent is movere, which means "to move." Motivation is defined as the desire to move rather than remain stationary. It can also be internal, emanating from a personal desire to achieve success independent of external rewards and enticements. Sometimes it can be simplistic and stems from a passion for notoriety, stardom, or financial rewards.

Motivation is a process of various degrees of self-determination known as behavioral regulation, with motivation and internal motivation at the extremes and four types of external law in between. This approach provides a better understanding of motivation than the internal-external dichotomy. More self-determined regulations (internal motivation and identification) are assumed to be associated with more positive psychological functioning, while moral variables are not exempted. An athlete who participates in sports for the pleasure of doing so, rather than for the external benefits (recognition, gratification), should be more inclined to show respect for others and follow written and unwritten rules of sports ethics, and less likely to follow a winto-win philosophy (Kavussanu \& Stanger, 2017).

Researchers realized that sportsmanship and self-determined motivation were linked in two ways: (selfdetermined) motives for participating in sports had a more significant impact on sportsmanship than the other way around. According to the authors, needs were a positive predictor of autonomous motivation, which was a positive predictor of sportsmanship attitudes and a negative predictor of anti-social moral attitudes. To many authors, the best knowledge of motivation has been linked to establishing the between karate sports and martial arts self-determined motivation and honest attitudes. 
DOI: $\underline{10.51386 / 25815946 / \mathrm{ijsms}-\mathrm{v} 4 \mathrm{i} 3 \mathrm{p} 119}$

Volume: 4 Issue: 3

May to June 2021

www.ijsmsjournal.org

According to Pagdato et al. (2021), motivation is the driving force behind all human behavior; it refers to the dynamics of one's actions, including the individual's needs, desires, and aspirations. Talented performers naturally aspire to be great because they have energy and motivation and a strong sense of hope.

According to Schunk et al. (2008), the essence of motivation is that humans are born with the capacity and motivation to experience joy or happiness as a result of their actions or responses. However, as people age, there are wide variations, or individual enjoyment, in the degree to which they seek mastery of experiences such as sport or enjoy the positive effect that comes with those experiences.

Furthermore, students or individuals participating in Karate or any sport have external motivators that outweigh internal motivators. External motivators appear to compel coaches, trainers, and institutions to award participants with awards or collaborative scholarships that are required at school. Internal motivation can take the form of student interests and student-owned time sacrifice for Karate training (Reeve, 2009). These external motivational strategies can help students and individuals develop a stronger internal drive to continue training and compete in Karate-do tournaments (Ryan \& Deci, 2000).

\section{METHODOLOGY AND METHODS}

In this study, the descriptive survey research design was used, with a questionnaire and observation guide as data collection techniques. A total of 138 Karate-do students represented the participants at the Limketkai Mall in Cagayan de Oro City. Percentages, weighted meanings, and the A--ratio for r. (at .05 alpha) were used to analyze the data.

\section{RESULTS AND DISCUSSION}

The following tables present the findings of results and discussions regarding the profile and the correlation of the variables used.

\section{A. The Respondents' Profile}

Table 1 reveals the respondents' profile in terms of their age, sex, length of training, highest level of Participation. As can be gleaned from table, $18-21$ years which is 44 or $31.90 \%$ belonged to the majority of participants age bracket; the rest are at least 10 - 13 years 30 or $21.70 \%$.

Table 1. Distribution of the Respondents Profile

\begin{tabular}{|l|c|c|}
\hline \multicolumn{1}{|c|}{ Indicator } & $\begin{array}{c}\text { Frequency } \\
\text { (f) }\end{array}$ & $\begin{array}{c}\text { Percent } \\
(\%)\end{array}$ \\
\hline Age & 30 & $21.70 \%$ \\
\hline $22-25$ & 44 & $31.90 \%$ \\
\hline $18-21$ & 34 & $24.70 \%$ \\
\hline $14-17$ & 30 & $21.70 \%$ \\
\hline $10-13$ & $\mathbf{1 3 8}$ & $\mathbf{1 0 0 . 0 0 \%}$ \\
\hline Total & 72 & $52.20 \%$ \\
\hline Gender & 66 & $47.80 \%$ \\
\hline Male & $\mathbf{1 3 8}$ & $\mathbf{1 0 0 . 0 0 \%}$ \\
\hline Female & 11 & $8.00 \%$ \\
\hline Total & 48 & $34.80 \%$ \\
\hline Length of Training & 79 & $57.20 \%$ \\
\hline $11-15$ years & $\mathbf{1 3 8}$ & $\mathbf{1 0 0 . 0 0 \%}$ \\
\hline $6-10$ years & 98 & $71.00 \%$ \\
\hline $1-5$ years & 40 & $29.00 \%$ \\
\hline Total & $\mathbf{1 3 8}$ & $\mathbf{1 0 0 . 0 0 \%}$ \\
\hline Highest Level of Participation & \\
\hline National & \\
\hline Local & \multicolumn{2}{|c|}{} \\
\hline Total & \multicolumn{2}{|c|}{} \\
\hline \multicolumn{2}{|c|}{} \\
\hline
\end{tabular}


DOI: $\underline{10.51386 / 25815946 / \mathrm{ijsms}-\mathrm{v} 4 \mathrm{i} 3 \mathrm{p} 119}$

Volume: 4 Issue: 3

May to June 2021

www.ijjsmsjournal.org

This could imply that Karate-do athletes are permitted to begin participating at the earliest possible age in order to be properly prepared and able to compete in any tournaments. This finding is consistent with Cynarski's (2012) findings that the factors that motivate young people to participate in martial arts/Karate-do practice are related to the desire to improve physical fitness, acquire fighting skills, meet interesting people, and compete in sports, due to their age and exposure to early training, as well as acceptance by the karate/martial arts group.

For the gender results, it indicated that most of the respondents were male, with a frequency of 72 or $52.20 \%$, while 66 respondents, or $47.80 \%$, were female. This result implies that male participants out number female participants in the karate-do tournament, possibly because they are more motivated and aggressive than female athletes. Hence, the findings on gender differences in participation motivation from the present study with their living environment - like a big urban city with the largest population in the USA are unique and have important referential values. In the study of Vertonghen and Theeboom (2010), which focuses on judo and karate, they found out that there are no significant differences between the genders in terms of participants' main participation motivations, and they summarized that 'self-defense' and 'physical fitness' were the two most important individual factors of motivation. Similar results exist between gender-level male kata and female Kumite karateka on peak power output, aggression and motivation measured by the Wingate test (Doria et al., 2009). In addition, the same result was found among karate athletes, who demonstrated higher attack and motivation in males than female athletes in both kata and Kumite (Sterkowicz-Przybycien, 2010).

These findings would appear to support the trend apparent for physical activities that identified that despite the involvement participation rates in females, the mean number of sessions of physical activity undertaken per week similar (3.6 for females and 3.2 for males) (Australian Sports Commission, 2005).

Only 79 or $57.20 \%$ of the respondents had a short length of training for $1-5$ years, while 11 or $8 \%$ had $11-15$ years of training experience. This indicates that the majority of the respondents had adequate and recommended years of training experience for them to be motivated to participate in the said tournament. According to the data above, more participants trained for five (5) years, indicating that the majority of the respondents were new members of their organization who devoted their time and training to growing up by fighting in national games. This supports the findings of the Breese (2008) survey, which stated that the length of involvement in martial arts was used to reflect the level of achievement and motivation within the karate-do practiced in subsequent analyses, as has been done in previous publications.

This relative length of training has been confirmed and supported by the work of various researchers who claim that it depends on the overall time athletes are involved in, with those interested in more than personal power and control being identified as their primary motivation for many years. In contrast, those who engaged for less than two years identified fitness as their primary motivation (Wasik, 2014).

In terms of the highest level of participation among the respondents, 98 or $71 \%$ participated in national play, while 40 or $29 \%$ participated in local play. This could be due to their adequate support and motivation for Karate -do fighters that motivates them to always try their best to make sure they play internationally.

\section{B. Respondent's level of Aggression}

The frequency and percentage distribution of the respondents according to their level of aggression as presented below:

Table 2. Summary of Respondents level of Aggression

\begin{tabular}{|l|c|c|c|}
\hline $\begin{array}{c}\text { Level of Aggression } \\
\text { Indicator }\end{array}$ & Frequency & Percentage & Description \\
\hline $119-141$ & 45 & 31.20 & Very High Aggression \\
\hline $96-118$ & 38 & 27.50 & High Aggression \\
\hline $73-95$ & 51 & 37.00 & Moderate Aggression \\
\hline $50-72$ & 2 & 1.40 & Low Aggression \\
\hline $27-49$ & 4 & 2.90 & Very Low Aggression \\
\hline
\end{tabular}


DOI: $\underline{10.51386 / 25815946 / \mathrm{ijsms}-\mathrm{v} 4 \mathrm{i} 3 \mathrm{p} 119}$

Volume: 4 Issue: 3

May to June 2021

www.ijjsmsjournal.org

The majority of the respondents had an average level of aggression with a frequency of 73-95 or $37.00 \%$. This means that despite having high motivation in their performance as reflected in table 1.6, the respondents have displayed a level of aggression in an instrumental way to win. According to Berkowitz (1993), aggression has two kinds: hostile and instrumental. Hostile is to harm, while instrumental is to obtain some external goal, such as victory and honour. Hence, it might be that the aggression displayed by the respondents during actual competition is instrumental in nature (Cox, 2002).

According to Kuan and Roy (2007), successful competitors showed more anger than less successful ones. However, in this study, aggression, which is "anger," was used positively, namely the energy needed to win a karate competition. It is not possible to infer from these findings that competitors feel angry but do so because of the desire to win the tournament.

Earlier studies of aggression in athletes discovered that athletes in high contact sports, such as football, Karate, judoka, or wrestlers were more aggressive in sports and daily life than athletes who participate in low or medium-contact sports Reynes \& Lorant (2001). They also found that in karate/martial arts, aggression is moderate for the duration of practice in the sport. Possessing the right level of aggressive attitude is a serious goal among karateka. In fact, I think it is better to have something like an abundance of that attitude than to lack it.

\section{Respondent's level of Motivation}

Table 3 shows the frequency and percentage distribution of the respondents according to their sports performance.

Table 3. Summary of Respondents level of Motivation

\begin{tabular}{|c|c|c|l|}
\hline $\begin{array}{c}\text { Motivation } \\
\text { Indicators }\end{array}$ & Frequency & Percentage & Description \\
\hline $71-91$ & 97 & $70.30 \%$ & High Motivation \\
\hline $50-70$ & 40 & $29.00 \%$ & Moderate Motivation \\
\hline $29-49$ & 1 & $00.70 \%$ & Very Low Motivation \\
\hline Total & 138 & $100.00 \%$ & \\
\hline
\end{tabular}

Majority of the respondents have high level of motivation with 97 or $70.30 \%$ while 1 or .70\% had low level of motivation.

These further deduce that majority of the respondents have been motivated to fight and displayed a good performance as reflected in table 3 that most of them have high motivation. The respondents might have displayed such motivation because of personal achievement and self-promotion. Coakley (2009) sports participation emphasizes personal achievement and self-promotion. In such a way, it is self-indulgent.

Furthermore, Rosa (2012) explained that individuals who were primarily motivated by competence to exercise to impart training and enjoyment (this same desire to have fun) could be classified as intrinsically motivated. On the other hand, extrinsically motivated people have an intrinsic motivation that seeks rewards or consequences apart from the behaviour itself.

Breese (2008) also demonstrated that when athletes first start participating in a sport, they are motivated by intrinsic and extrinsic factors. On the other hand, some sports may rely more on intrinsic motivation than extrinsic motivation. 
DOI: $\underline{10.51386 / 25815946 / \mathrm{ijsms}-\mathrm{v} 4 \mathrm{i} 3 \mathrm{p} 119}$

Volume: 4 Issue: 3

May to June 2021

www.ijjsmsjournal.org

D. Correlation Analysis between Moderating and Independent Variables

Table 4. Correlation between Moderating Variables and Independent Variable

\begin{tabular}{|c|c|c|c|c|c|c|}
\hline $\begin{array}{c}\text { Independent } \\
\text { Variables }\end{array}$ & \multicolumn{5}{|c|}{ Level of Motivation } & \multicolumn{3}{c|}{ Level of Aggression } \\
\hline $\begin{array}{c}\text { Moderating } \\
\text { Variables }\end{array}$ & r-value & p-value & Relationship & r-value & p-value & Relationship \\
\hline Age & .137 & .108 & NS & .005 & .955 & NS \\
\hline Gender & .061 & .478 & NS & -.002 & .982 & NS \\
\hline $\begin{array}{c}\text { Highest level of } \\
\text { Participation }\end{array}$ & -117 & .171 & NS & .015 & .865 & NS \\
\hline $\begin{array}{c}\text { Length of Years } \\
\text { of Training }\end{array}$ & .184 & .031 & $*$ & .415 & .000 & $* *$ \\
\hline $\begin{array}{c}\text { LEGEND: } \\
\text { NS } \\
*\end{array}$ & $\begin{array}{c}\text { No Significant Relationship } \\
\text { Significant } a=.05 \\
\text { Significant } a=.01\end{array}$ \\
\hline
\end{tabular}

Table 4 displays the results of the analysis of data between the independent variables and moderating variables through the Moment Product Correlation Coefficient (Pearson r).

Of course, among the moderating variables, age, gender, and the highest level of participation show no significant relationship to the independent variable of motivation level for these results, we accept the second postulated null hypothesis (Ho2).

However, the moderating variable of the number of years of training is significantly related to the independent variables of level of motivation and level of aggression is significantly related to level of aggression. For these specific findings, it rejected Ho2.

The relationship existing level of motivation and number of years of training and level of aggression with number of years of training are said to be linear. This means that as years of training increase the respondents' motivation, at the same time, aggression tends to increase. So, the longer the respondents are trained in karatedo, the more they are motivated and they become more aggressive.

The motivation displayed by the respondents during the competition is both extrinsic and intrinsic. Extrinsic is for the rewards they will receive and intrinsic is for their own self-satisfaction or personal reasons. According to Cox (2002), it is external in nature and comes from a personal desire to find success independent of a desire to gain fame or financial rewards. Furthermore, Berkowitz (1993) added that aggression has two kinds: hostile and instrumental. Hostile is to harm, while instrumental is to obtain some external goal, such as victory and honor. Hence, it can be inferred that the level of aggression displayed by the respondents during actual competition is instrumental in nature.

\section{A. Conclusion}

\section{CONCluSions AND RECOMMENDATION}

Based on the findings, the following conclusions were drawn: The respondents ranged in age from 18 to 21 years old, were predominantly male karate-do practitioners, and had trained for 1 to 5 years, which was a significant factor in their participation in the game. The respondents are capable of fighting in both national and local games, but their ability needs to be improved and supported by the various organizations involved. 
DOI: $\underline{10.51386 / 25815946 / \mathrm{ijsms}-\mathrm{v} 4 \mathrm{i} 3 \mathrm{p} 119}$

Volume: 4 Issue: 3

May to June 2021

www.ijssmsjournal.org

\section{B. Recommendations}

The researchers recommended that Administrators of the Philippine Karate-do federation should conduct more invitational karate-do tournament either local or national to promote karate-do sports and to encourage more women to engage in karate-do; Coaches should possess good motivation strategy towards their athletes in order that athletes should not show aggressiveness during competition; Trainers must have a strategic training plan for their karate-do athletes; Karate-do athletes (beginners and advance) should constantly practice in order to enhance their skills and improve their performances. This study could be considered as an exploratory research to be used as a reference for future researches; similar studies should be conducted for comparison to come up with different results.

\section{ACKNOWLEDGMENT}

This research would not have been possible without the support of our dear College Dean, Dr. Hendely A. Adlawan. Her enthusiasm, knowledge, and exacting attention to detail have been an inspiration and kept our work on track from the first encounter. They shared important information about this study with our colleagues at the College of SPEAR Mindanao State University (Main), Marawi, Philippines. We were also grateful for the insightful comments offered by the anonymous peer reviewers and editorial board members of the IJSMS Journal. The unselfishness and creativity of one and all have improved this research in innumerable ways and saved us from many errors, those that inevitably remain our entire responsibility. Finally, we would like to express our gratitude to our families for their prayers, encouragement, and assistance in completing this study; God bless you all.

Ethics Approval: Researchers obtained a letter of consideration for this work from College of SPEAR MSU (Main) Ethical Review committee and from the organizer of Fit Well Zone Tournament Performance in Cagayan De Oro.

Conflict of Interest: Researchers declared no conflicts of interest.

OrCID iDs: $\quad 0000-0002-3444-4713$.

\section{REFERENCES}

[1] Australian Sports Commission, (2005) Participation in Exercise, Recreation and Sport Annual Report 2004. Standing Committee on Recreation and Sport 2005, Australian Government. Avaliable from URL: www.ausport.gov.au/scorsresearch/ERASS2004/ERASS2004.pdf.

[2] Basiaga-Pasternak, J., Szafraniec, Ł., Jaworski, J., \& Ambroży, T. (2020). Aggression in competitive and noncompetitive combat sports athletes. I do Movement for Culture. Journal of Martial Arts Anthropology, 20(2), 17-23.

[3] Berkowitz, L. (1993). Aggression: Its causes, consequences and control. New York, NY; McGraw-Hill.

[4] BlomqvistMickelsson, T. (2020). Modern unexplored martial arts - what can mix martial arts and Brazilian Jiu-Jitsu do for youth development? European Journal of Sport Science, 20(3), 386-393.

[5] Breese, H. P. (2008). Participation motivation in ITFNZ Taekwon-Do: A study of the central districts' region. Massey University, NZ.

[6] Cashmore, E. (2002). Sports Psychology: the key concepts. Routledge. 1:10-13

[7] Coakley, J. (2009). Sports in society: Issues and controversies (10th ed.). New York, NY: McGraw-Hill.

[8] Cox, R. H. ((2002). Sport psychology: concepts and applications. (4th ed). Boston MA: McGraw-Hill.

[9] Cynarski, W. J. (2012). Values of martial arts in the light of the anthropology of martial arts. Journal of Combat Sports and Martial Arts, 3, 1-4. http://dx.doi.org/10.5604/20815735.1047608.

[10] Doria, C., Veicsteinas A., Limonta, E., et al. (2009). Energetics of karate (kata and kumite techniques) in top-level athletes. Eur J Appl Physiol. 107: 603-10.

[11] Hernandez J., \&Anderson K. B. (2015). Internal martial arts training and the reduction of hostility and aggression in martial arts students. Psi Chi Journal of Psychological Research, 20(3), 169-176.

[12] Kavussanu, M., \& Stanger, N. (2017). Moral behavior in sport. Current Opinion in Psychology, 16, $185-192$.

[13] Kordi, R.., Maffuli, N., Wroble, R.R \& Wallace, W.A. (2009). Combat Sports Medicine. London: Springer. 


\section{DOI: $\underline{10.51386 / 25815946 / i j s m s-v 4 i 3 p 119}$}

Volume: 4 Issue: 3

May to June 2021

www.ijsmsjournal.org

[14] Kuan, G \& Roy, J. (2007) Goal profiles, mental toughness and its influence on performance outcomes among Wushu athletes. Journal of Sports Science and Medicine 6, 28-33.

[15] Pagdato, V. J., Gallardo, M., Fadare, A.S \& Adlawan, A.H. (2021). Motivation and Mental Toughness among Table Tennis Athletes: Achievement in Sports Performance. International Journal of Science and Management studies. (IJSMS), 4(3), 162-170.

[16] Reeve, J. (2009). Why teachers adopt a controlling motivating style toward students and how they can become more autonomy supportive. Educational Psychologist, 44(3), 159-175.

[17] Reynes E, Lorant J. (2001). Do competitive martial arts attract aggressive children? Perceptual Motor Skills. 93(2):382-6

[18] Republic Act No. 9850. (2009). http://www.gov.ph/2009/12/11/republic-act-no-9850/ (Accessed on April 16, 2021).

[19] Rosa, V. A. V. (2012). Samurais “in modern Europe: motivations and understanding of Portuguese karateka-do Movement for Culture. Journal of Martial Arts Anthropology, 12, 11-19.

[20] Ryan, R. M., \& Deci, E. L. (2000). Intrinsic and extrinsic motivations: Classic definitions and new direction. Contemporary Educational Psychology, 25(1), 54-67. doi: 10.1006/ceps.1999.1020.

[21] Sadock, B.J. (2009). Signs and Symptoms in Psychiatry. In: Sadock BJ, Sadock VA, Ruiz P, eds. Kaplan \& Sadock's Comprehensive Textbook of Psychiatry. 9th ed. Philadelphia: Wolters Kluwer Lippincott Williams \& Wilkins Press.

[22] Schunk, D. H., Pintrich, P. R. \& Meece, J. L. (2008). Motivation in education: Theory, research, and applications. Upper Saddle River, NJ: Pearson Education.

[23] Sterkowicz-Przybycien, K. (2010). Physical and Physiological Profile of Elite Karate Athletes. Available from: https://www.researchgate.net/publication/230696208_Physical_and_Physiological_Profile_of_Elite_Karate_Athletes [accessed Jun 212021$]$

[24] Sudesh, B., \& Rathee, N. K. (2013). Optimizing aggression in combative sports - an analytical approach. Journal of Physical Education and Sport, 13(2), 153-156.

[25] Vertonghen, J \& Theeboom, M. (2010). The social-psychological outcomes of martial arts practice among youth: a review. Journal of Sports Science and Medicine. 9, 528-537.

[26] Wann, D. (2005). Essay aggression in sport. Med Sport. 366(1), 31-2.

[27] Wasik, J. (2014). Three areas of Taekwondo identification and practice. I do Movement for Culture. Journal of Martial Arts Anthropology, 14, 22-26.

[28] World Karate Federation. (2012). Kata and Kumite competition rules, revision 7.1. P:11. http://karateserbia.org/wordpress/wpcontent/uploads/2012/01/KATA-KUMITE-COMPETITION-RULES-7.1.pdf. (Accessed on April 14, 2021). 